\title{
Temperature scaling concept of MOSFET
}

\author{
K. Masu and K. Tsubouchi
}

Research Institute of Electrical Communication, Tohoku University, Katahira 2-1-1, Aoba-ku, Sendai 980 , Japan

\begin{abstract}
Lowering both the threshold voltage $\left(\mathrm{V}_{\mathrm{th}}\right)$ and subthreshold swing $(\mathrm{S})$ at the same time is essentially required for $0.1 \mu \mathrm{m}$ and below $0.1 \mu \mathrm{m}$ MOSFETs with low supply voltage. In this paper, we discuss a temperature scaling concept of MOSFET and the device characteristics of the fabricated $77 \mathrm{~K}$ MOSFETs. In the temperature scaling concept, the physical quantities relating to potential are scaled with operation temperature, while the dimensional quantities are constant. The distribution of mobile carrier concentration are kept constant. In order to design 0.1 $\mu \mathrm{m}$ MOSFET with low supply voltage, we proposed the temperature-dimension combination scaling theory (CST). The $77 \mathrm{~K}$ MOSFET with supply voltage of $1-\mathrm{V}$ has been designed from a $300 \mathrm{~K}$ parent device on the basis of the combination scaling theory. The fabricated $77 \mathrm{~K}-\mathrm{CST} 0.18 \mu \mathrm{m}$ MOSFET has exhibited fully scaled characteristics. The subthreshold swing (S) and the threshold voltage $\left(V_{t h}\right)$ of this device is achieved to be $27 \mathrm{mV} / \mathrm{dec}$ and $0.21 \mathrm{~V}$ without degradation of $S$ and $V_{\text {th }}$ due to the short-channel-effects degradation.
\end{abstract}

\section{INTRODUCTION}

In $0.1 \mu \mathrm{m}$ and below $0.1 \mu \mathrm{m}$ MOSFET era, low-voltage operation $(-1 \mathrm{~V})$ is essentially required in order to avoid high-electric-field degradation as well as to achieve low power dissipation. The threshold voltage $\left(\mathrm{V}_{\mathrm{th}}\right)$ and subthreshold swing (S) should be both scaled down with the reduced supply voltage $\left(\mathrm{V}_{\mathrm{DD}}\right)$. Simple requirement is that $V_{\text {th }}$ is greater than (5 6) $\times S$ for a sufficient on/off current ratio, and $\mathrm{V}_{\mathrm{th}}$ is less than $0.2 \times \mathrm{V}_{\mathrm{DD}}$ for high-speed performance, i.e. $\mathrm{V}_{\mathrm{th}}$ for $1-\mathrm{V}$ operation is needed to be $\sim 0.2 \mathrm{~V}$. Furthermore, degradation of $\mathrm{V}_{\mathrm{th}}$ and $S$ due to the short channel effects (SCE) should be substantially suppressed. The scaling rule has been a guiding principle for miniaturizing the device dimensions. ${ }^{1,2)}$ However, at room temperature, scaling of $\mathrm{V}_{\text {th }}$ and $\mathrm{S}$ for low $\mathrm{V}_{\mathrm{DD}}$ is hardly attainable in simple planer type $0.1 \mu \mathrm{m}$ MOSFETs. The reasons are (1) unscaled $S$ of
$60 \sim 80 \mathrm{mV} / \mathrm{dec}$ at room temperature, (2) contradictory requirement for substrate doping: low doping density for low $\mathrm{V}_{\text {th }}$ and high density for suppression of short channel effects, and (3) unscalable parameter of built-in potential $\left(\phi_{\mathrm{bj}}\right)$ of pn junction. ${ }^{3)}$

Low temperature (LT) operation is promising for high-speed MOSFET circuits because of higher transconductance and low wiring resistance. $^{4-10)}$ The significance of LT-MOSFET should be re-recognized as its stcep subthreshold swing (S) of $\mathrm{S} \sim 20 \mathrm{mV} / \mathrm{dec}$ at $77 \mathrm{~K}$. However, lowering $V_{\text {th }}$ is still hardly achieved because of the contradictory requirement for substrate doping and the unscaled $\phi_{b i}$. Although $77 \mathrm{~K} 0.1 \mu \mathrm{m}$ MOSFETs with low $V_{D D}$ have been developed, scaling $V_{\text {th }}$ and $S$ with the SCE suppression has not been fully addressed.

We have proposed the temperature scaling theory (TST) as a design concept of $77 \mathrm{~K}$ MOSFET with low supply voltage. ${ }^{11-14)}$ 
Simulation and experimental results have shown that $\mathrm{V}_{\mathrm{fh}}, \mathrm{S}$, and the SCE degradation of $77 \mathrm{~K}-\mathrm{TST}$ device are all scaled down to $77 \mathrm{~K} / 300 \mathrm{~K} \approx 1 / 4$, as compared with those of $300 \mathrm{~K}$ device. ${ }^{15-17)}$ For miniaturizing $77 \mathrm{~K}$ MOSFET down to $0.1 \mu \mathrm{m}$ regime, we have also proposed the temperaturedimension combination scaling theory (CST). ${ }^{11,12)}$ The fabricated 77K-CST devices have exhibited no SCE degradation of $S$ and $V_{\text {th }}$ at the channel length down to $0.18 \mu \mathrm{m} .^{18,19)}$

In this paper, we discuss the temperature scaling concept and the device characteristics of fabricated 77K MOSFETs designed based on the temperature scaling theory (TST) and the temperature-dimension combination scaling theory (CST).

\section{TEMPERATURE SCALING CONCEPT}

\subsection{Temperature scaling theory (TST)}

We have clearly recognized that there are three essential factors in the scaling concept: the scaling quantity, the fundamental equation, and the conservative quantity. As listed in Table 1 , in the conventional dimensional scaling, the scaling quantity is dimension and the fundamental equation is Poisson's equation. On the other hand, in the temperature scaling, the scaling quantity is temperature and the fundamental equation is Fermi-Dirac distribution function as discussed in this section in detail. Therefore, the

Table 1. Three essentials in the scaling concept

\begin{tabular}{l|l|l}
\hline & $\begin{array}{c}\text { Dimensional } \\
\text { Scaling }\end{array}$ & $\begin{array}{c}\text { Temperature } \\
\text { Scaling }\end{array}$ \\
\hline $\begin{array}{l}\text { Scaling } \\
\text { quantity }\end{array}$ & Dimension & Temperature \\
\hline $\begin{array}{l}\text { Fundamental } \\
\text { equation }\end{array}$ & $\begin{array}{l}\text { Poisson's } \\
\text { equation }\end{array}$ & $\begin{array}{l}\text { Fermi-Dirac } \\
\text { distribution } \\
\text { function }\end{array}$ \\
\hline $\begin{array}{l}\text { Conserva- } \\
\text { tion quantity }\end{array}$ & $\begin{array}{l}\text { Electric field } \\
\text { distribution, or } \\
\text { potential distri- } \\
\text { bution }\end{array}$ & $\begin{array}{l}\text { Mobile carrier } \\
\text { distribution }\end{array}$ \\
\hline
\end{tabular}

dimensional and the temperature scaling concepts are fundamentally independent of each other. Figure 1 shows the relation between the temperature and the conventional scalings schematically.

The temperature scaling are derived as follows: ${ }^{11,12)}$ At first, we recognized the FermiDirac distribution function as a basis for considering the temperature scaling. The FermiDirac distribution function $\mathrm{f}$ is

$$
f=1 /\left[1+\left\{\mathrm{q}\left(\phi_{\mathrm{f}}-\phi\right) / \mathrm{kT}\right],\right.
$$

where $f$ is the probability and $\phi_{\mathrm{f}}$ the quasi Fermi potential. From eq. (1), one can see the probability $f$ is determined by the ratio of the potential to the thermal voltage $k T / q$. In other words, $f$ will not change if the potential is varied in proportion to the temperature. For a MOSFET, since the boundary condition of the mobile carrier is nearly independent of temperature, the distribution of the mobile carrier will be maintained constant. Therefore, the current voltage characteristics will be scaled down if the potential is reduced in proportion to the operation temperature. Although the holes in the bulk region are partly frozen out at $77 \mathrm{~K}$, the acceptors in the surface depletion region are completely ionized at $300 \mathrm{~K}$ and $77 \mathrm{~K}$ due to the band bending. The electrons in the degenerately doped source and drain region are not frozen out. Therefore, freeze-out effect in the bulk does not

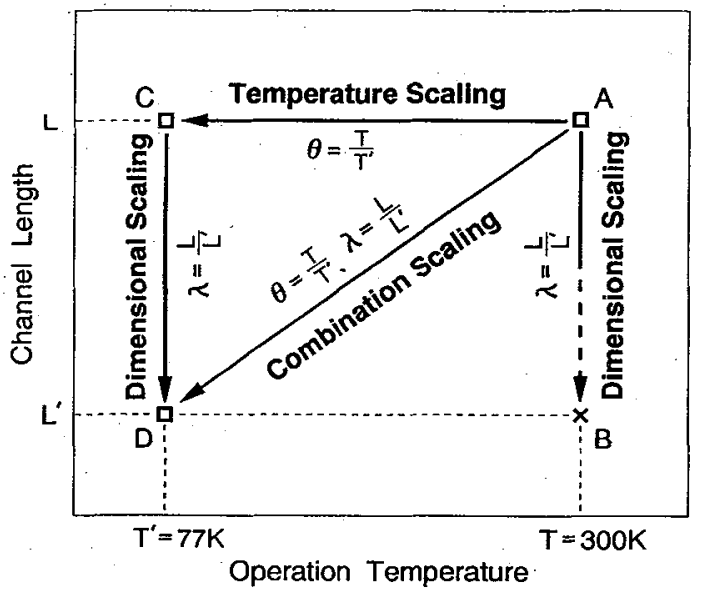

Fig. 1.

The relation between the temperature, the dimensional, and combination scalings. 
affect the enhancement MOSFET characteristics. ${ }^{4)}$

We have introduced the temperature scaling factor ${ }^{11,14)}$ defined as

$$
\theta=\mathrm{T} / \mathrm{T},
$$

where $T^{\prime}$ is the new temperature, e.g., $T=300 \mathrm{~K}$ and $T^{\prime}=77 \mathrm{~K}$, then $\theta=300 \mathrm{~K} / 77 \mathrm{~K} \sim 4$. The new supply voltage $\left(\mathrm{V}_{\mathrm{DD}}\right)$ should be $\mathrm{V}_{\mathrm{DD}}{ }^{\prime}=\mathrm{V}_{\mathrm{DD}} / \theta$. In order to maintain the width of the depletion layer at the $p n$ junction, the substrate doping concentration $\left(\mathrm{N}_{\mathrm{A}}\right)$ should be decreased by $\theta$. The potential barrier of the $p n$ junction can be scaled down by adding the forward substrate bias $\left(\mathrm{V}_{\mathrm{sb}}\right)$,

$$
\phi_{\mathrm{bi}}^{\prime}-\mathrm{V}_{\mathrm{sb}}^{\prime}=\left(\phi_{\mathrm{bi}}-\mathrm{V}_{\mathrm{sb}}\right) / \theta,
$$

where $\phi_{\mathrm{bi}}$ and $\phi_{\mathrm{bi}}{ }^{\prime}$ are the built-in potential, $\mathrm{V}_{\mathrm{sb}}$ and $\mathrm{V}_{\mathrm{sb}}{ }^{\prime}$ are the substrate bias. The meaning of applying the forward substrate bias is to scale the built-in potential effectively. The surface potential $\phi_{\mathrm{s}}=2 \phi_{\mathrm{F}}-\mathrm{V}_{\mathrm{sb}}$ is also scaled down by the forward substrate bias. The threshold voltage $\left(\mathrm{V}_{\mathrm{th}}\right)$ is given by

$$
\begin{aligned}
\mathrm{V}_{\mathrm{th}}= & \mathrm{V}_{\mathrm{FB}}+2 \phi_{\mathrm{F}} \\
& +\left(2 \varepsilon \varepsilon_{\mathrm{o}} \mathrm{qN} \mathrm{N}_{\mathrm{A}}\right)^{1 / 2}\left(2 \phi_{\mathrm{F}}-\mathrm{V}_{\mathrm{sb}}\right)^{1 / 2} / \mathrm{C}_{\mathrm{oX}}
\end{aligned}
$$

where $V_{F B}$ is the flat-band voltage, $\varepsilon_{0}$ the permittivity of vacuum, $\varepsilon$ the relative permittivity of silicon. $V_{F B}+2 \phi_{F}$ is nearly $0 \mathrm{~V}$ for $n^{+}$-poly-Si gate NMOSFET and $\mathrm{p}^{+}-$poly-Si gate PMOSFET. The third term of eq. (4) is scaled down by $\theta$. The threshold voltage $V_{t h}$ is, accordingly, scaled down by $\theta$ approximately.

The inversion layer thickness is also varied with temperature. If a parabolic potential distribution $^{21)}$ at the channel region is assumed, it can be approximately given by

$$
\mathrm{t}_{\mathrm{inv}}=(\mathrm{kT} / \mathrm{q})\left(\varepsilon \varepsilon_{\mathrm{o}} / 2 \mathrm{qN} \mathrm{N}_{\mathrm{A}} \phi_{\mathrm{S}}\right)^{1 / 2}
$$

where $t_{\text {inv }}$ is the thickness of the inversion layer. In eq. (5), the scaling effects of $\mathrm{T}, \mathrm{N}_{\mathrm{A}}$, and $\phi_{\mathrm{S}}$ cancel out, i.e., the thickness of the inversion layer is kept constant under the temperature scaling.

The temperature scaling factors are summarized in the left column of Table 2 . The

Table 2. Scaling factors of important physical quantities.

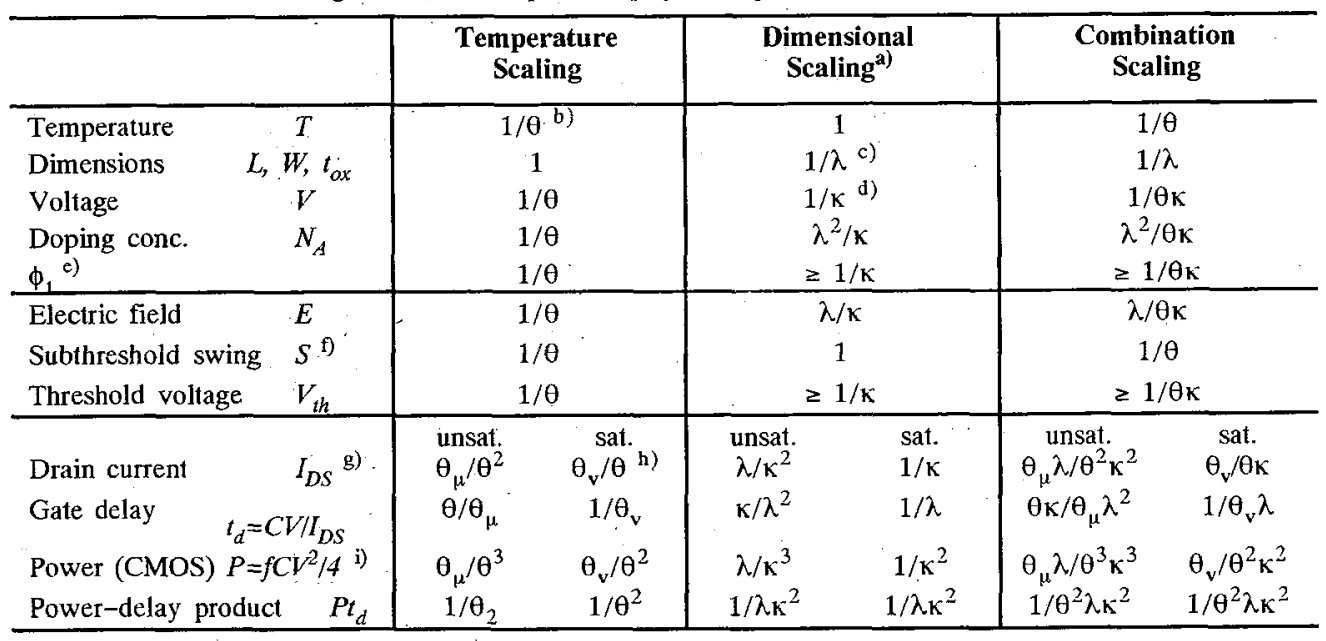

a) G. Baccarani, et al., IEEE ED-31, 452, (1984).

b) $\theta$ : temperature scaling factor, $\theta=300 \mathrm{~K} / 77 \mathrm{~K} \approx 4$.

c) $\lambda$ : dimensional scaling factor, $\lambda=\mathrm{L}$ (long)/L(short).

d) $\kappa$ : voltage scaling factor, $\kappa=V$ (long) $/ \mathrm{V}$ (short).

e) $\phi_{\mathrm{t}}=\phi_{\mathrm{bi}}-V_{\mathrm{sb}}$, where $\phi_{\mathrm{bi}}$ is the built-in potential of the pn junction, $\mathrm{V}_{\mathrm{sb}}$ the forward substrate bias. f) $S=\log _{\mathrm{e}} 10(\mathrm{kT} / \mathrm{q})\left(1+\mathrm{C}_{\mathrm{D}} / \mathrm{C}_{\mathrm{ox}}\right)$

g) (unsat.) $\mathrm{I}_{\mathrm{DS}}=(\mathrm{W} / \mathrm{L}) \mu \mathrm{C}_{\mathrm{ox}}\left(\mathrm{V}_{\mathrm{G}}-\mathrm{V}_{\mathrm{th}}\right) \mathrm{V}_{\mathrm{DS}}$ (sat.) $\quad \mathrm{I}_{\mathrm{DS}}=\mathrm{k}_{\mathrm{s}} \mathrm{WC}_{\mathrm{ox}}\left(\mathrm{V}_{\mathrm{G}}-\mathrm{V}_{\mathrm{th}}\right) \mathrm{v}_{\mathrm{s}}$

h) $\theta_{\mathrm{v}}=\mathrm{v}_{\mathrm{s}}(77 \mathrm{~K}) / \mathrm{v}_{\mathrm{s}}(300 \mathrm{~K})-1.3$, $\theta_{\mu}=\mu(77 \mathrm{~K}) / \mu(300 \mathrm{~K})=2-3$

i) Frequency $f$ is assumed to be proportional to $I / t_{d}$. 
temperature scaling theory (TST) is related to the operation temperature, which gives a quantitative relationship between the temperature and device parameters. Since the physical quantities relating to potential is scaled with the temperature, the mobile carrier concentration is maintained constant. In the temperature scaling concept, the scaling quantity is temperature, the fundamental equation is Fermi-Dirac distribution function, and the conservative quantity is the mobile carrier distribution. It can be concluded that the temperature and the conventional scaling concepts relating to device dimension are independent of each other as summarized in Table 1 and Fig. 1.

We have developed the 2-dimensional and 3dimensional device simulation program (COLD2 and COLD3 (a COmputer simulation program for Low temperature operated Devices in 2 or 3 dimensions) which can be used for the analysis of low temperature MOSFETs. ${ }^{15)}$

Figure 2 shows simulated $I_{D}$ vs. $\left(V_{G}-V_{t h 0}\right)$ curves calculated by COLD2. The simulation is performed for an $n$-channel MOSFET. The

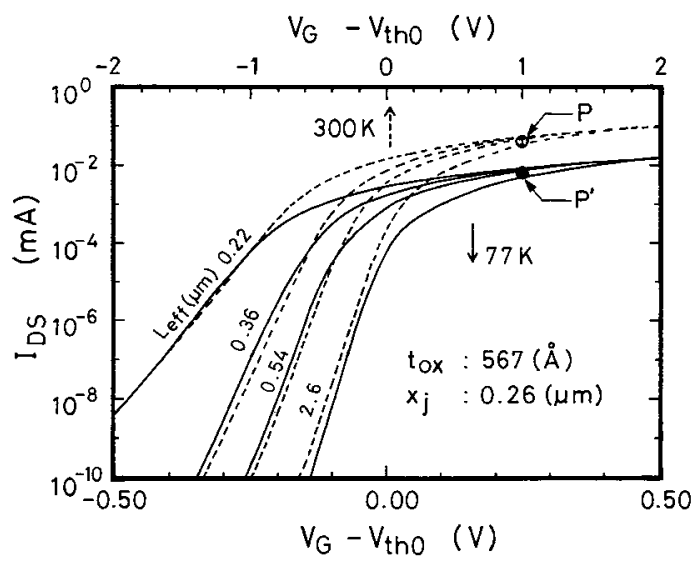

Fig. 2.

$I_{D}$ vs. $\left(V_{G}-V_{\text {th } 0}\right)$ curves for various channel lengths. Dashed lines are for $300 \mathrm{~K}$ with $\mathrm{N}_{\mathrm{A}}=8 \times 10^{15} \mathrm{~cm}^{-3}$, $\mathrm{V}_{\mathrm{DS}}=1 \mathrm{~V}, \mathrm{~V}_{\mathrm{sb}}=0 \mathrm{~V}$, and $\mathrm{V}_{\mathrm{th0}}=1.6 \mathrm{~V}$. Solid lines are for $77 \mathrm{~K}$ with $\mathrm{N}_{\mathrm{A}}=2 \times 10^{15} \mathrm{~cm}^{-3}, \mathrm{~V}_{\mathrm{DS}}=0.25 \mathrm{~V}, \mathrm{~V}_{\mathrm{sb}}=0.75 \mathrm{~V}$, and $\mathrm{V}_{\text {tho }}=1.3 \mathrm{~V}$. The upper and lower axes of the abscissa correspond to $300 \mathrm{~K}$ and $77 \mathrm{~K}$, respectively. $V_{\text {tho }}$ is the threshold voltage for $2.68 \mu \mathrm{m}$ channel length. In the calculation, the value of electron mobility were taken to be constant, i.e., 1500 and $3000 \mathrm{~cm}^{2} / \mathrm{Vsec}$ at $300 \mathrm{~K}$ and $77 \mathrm{~K}$, respectively. upper and lower voltage axes of abscissa correspond to $300 \mathrm{~K}$ and $77 \mathrm{~K}$, respectively. I-V curves of $300 \mathrm{~K}$ and $77 \mathrm{~K}$ devices are clearly overlapped, i.e., $\mathrm{I}-\mathrm{V}$ curves of $77 \mathrm{~K}$ devices are scaled down with the operation temperature. Figure 3 shows the electron distribution at $P$ $\left(300 \mathrm{~K}, \mathrm{~V}_{\mathrm{DS}}=\mathrm{V}_{\mathrm{G}}-\mathrm{V}_{\text {th0 }}=1 \mathrm{~V}\right)$ and $\mathrm{P}^{\prime}(77 \mathrm{~K}$, $\mathrm{V}_{\mathrm{DS}}=\mathrm{V}_{\mathrm{G}}-\mathrm{V}_{\mathrm{th} 0}=0.25 \mathrm{~V}$ ) for $0.54 \mu \mathrm{m}$ MOSFET, where $V_{D S}$ is the drain-source voltage. It can be confirmed that the distribution of electron concentration is kept constant. The results of Fig. 2 means that the subthreshold swing $S$ and threshold voltage $V_{t h}$ is scaled down with the temperature.

Furthermore, we have confirmed by the three dimensional simulation (COLD3) that the $V_{\text {th }}$ roll-off and variation of the subthreshold swing $S$ due to the small size effects are also scaled down under the temperature scaling theory. ${ }^{15,16)}$
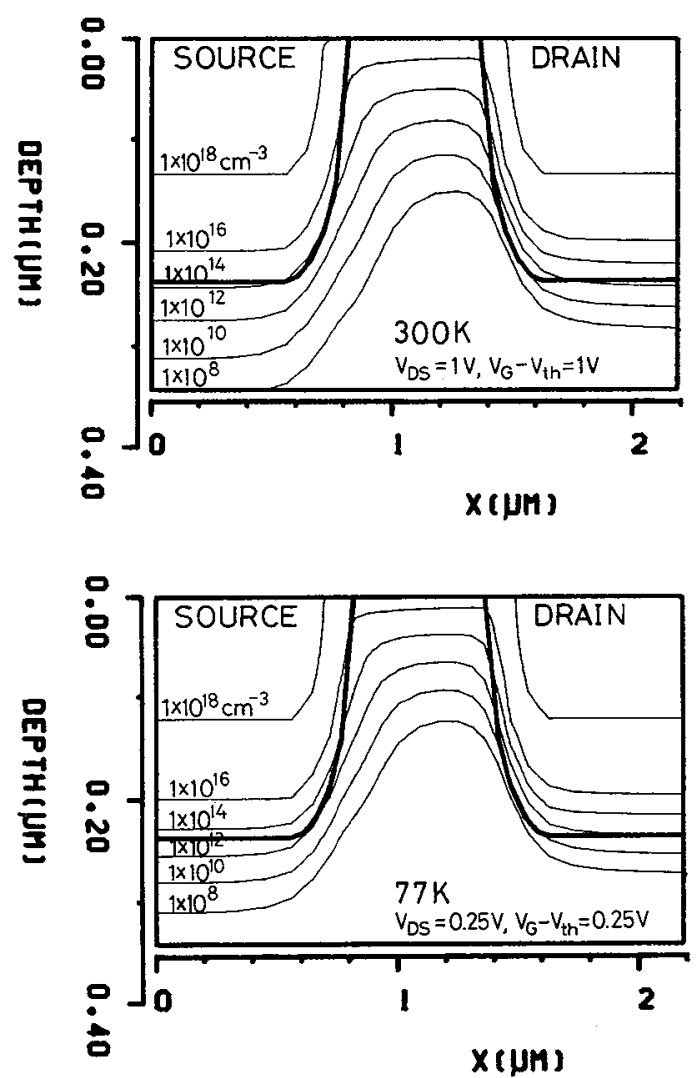

Fig. 3.

Electron distribution of $0.54 \mu \mathrm{m}$ MOSFET in Fig. 2. (P and $\mathrm{P}^{\prime}$ ) 


\subsection{Temperature-Dimension Combination Scaling Theory (CST)}

Table 2 summarizes the scaling factors of important physical quantities of the temperature scaling theory together with the conventional dimension scaling theory. Circuit performances such as drain current, delay time and power dissipation are also listed. In deep submicron MOSFET, since the electrons flow with the saturation velocity $\left(\mathrm{v}_{\mathrm{S}}\right)$, drain current is given by $\mathrm{I}_{\mathrm{DS}}=\mathrm{kv}_{\mathrm{s}} \mathrm{W}\left(\mathrm{V}_{\mathrm{G}}-\mathrm{V}_{\mathrm{th}}\right) \mathrm{V}_{\mathrm{DS}}$. In the temperature scaling regime, the gate delay time $\left(\mathrm{t}_{\mathrm{d}}\right)$ under the velocity saturated case becomes smaller by a factor $1 / \theta_{\mathrm{v}}=0.75$ in spite of the decrease of the supply voltage. Power dissipation of CMOS logic circuit is decreased by a factor of $1 / \theta^{2}$.

It is noted that the dimensional quantities are not scaled in the temperature scaling theory. In order to design $77 \mathrm{~K}$ ultrasmall devices, the dimensional scaling concept should be introduced into the temperature scaling concept. Since the temperature and the conventional dimension scaling concept are fundamentally independent of each other, the temperature-dimension combination scaling theory (CST) can be derived by combining the scaling factors of the temperature and the dimension scaling factors as listed in the right column of Table 2 . In Table 2 , the generalized dimension scaling theory ${ }^{22)}$ (DST) is listed; $\lambda$ is the dimensional scaling factor and $\kappa$ is the voltage scaling factor. $\kappa=\lambda$ corresponds to the constant electric-field scaling ${ }^{1)}$ and $\kappa=1$ corresponds to the constant voltage scaling.

As shown in Fig. 1, 77K 0.1 $\mu \mathrm{m}$ MOSFET can be designed from a $300 \mathrm{~K}$ device with the combination scaling theory. If the $300 \mathrm{~K}$ parent device has no degradation of $V_{t h}$ and $S$ due to the short channel effects (SCE), the 77K CST device is expected to have no SCE degradation. We have already shown by COLD 3 that $77 \mathrm{~K}$ device can be miniaturized to $0.1 \mu \mathrm{m}$ channel length without SCE degradation using CST. ${ }^{16)}$

\section{DEVICE CHARACTERISTICS OF FABRICATED 77K TST MOSFET}

In this section, we discuss the fabrication and the measured characteristics of 77K MOSFET's designed only with the temperature scaling theory (TST). ${ }^{17,18)}$

The device parameters of $77 \mathrm{~K}-\mathrm{TST}$ MOSFET's are designed based on those of $300 \mathrm{~K}$ devices as listed in Table 3. $\mathrm{N}^{+}$-poly-Si gate $\mathrm{n}-$ channel MOSFET's with the arsenic-doped single-drain structure were fabricated. $\mathrm{As}^{+}$ion was implanted at $120 \mathrm{KeV}$ and the implantation dose was $2 \times 10^{15} \mathrm{~cm}^{-2}$. After the implantation of $\mathrm{As}^{+}$ion, furnace annealing was carried out at $900^{\circ} \mathrm{C}$ for $30 \mathrm{~min}$ to activate the implanted impurities. The source and drain pn junction depths were estimated to be $0.3 \mu \mathrm{m}$ from SUPREM-III (Stanford University Process Engineering Model) simulation. The supply voltages for $300 \mathrm{~K}$ and $77 \mathrm{~K}$ were designed to be $4 \mathrm{~V}$ and $1 \mathrm{~V}$, respectively. The channel width (W) was $50 \mu \mathrm{m}$. Here, it is noted that the substrate doping concentration $\left(\mathrm{N}_{\mathrm{A}}\right)$, the gate oxide thickness $\left(\mathrm{T}_{\mathrm{ox}}\right)$ and the junction depth $\left(\mathrm{x}_{\mathrm{j}}\right)$ are kept constant with shrinking channel length (L), i.e., only the temperature scaling is applied in

Table 3.

Fabricated device parameters of $300 \mathrm{~K}$ and $77 \mathrm{~K}-$ TST devices.

\begin{tabular}{l|c|c|c}
\hline & $\begin{array}{c}300 \mathrm{~K} \\
\text { device }\end{array}$ & $\begin{array}{c}\text { Scaling } \\
\text { factors }\end{array}$ & $\begin{array}{c}77 \mathrm{~K}-\mathrm{TST} \\
\text { device }\end{array}$ \\
\hline $\mathrm{T}[\mathrm{K}]$ & 300 & $1 / \theta \sim 1 / 4$ & 77 \\
\hline $\mathrm{L}_{\mathrm{eff}}[\mu \mathrm{m}]$ & $0.3-10$ & 1 & $0.2-10$ \\
\hline $\mathrm{T}_{\mathrm{ox}}[\mathrm{nm}]$ & 25 & 1 & 25 \\
\hline $\mathrm{N}_{\mathrm{A}}\left[\mathrm{cm}^{-3}\right]$ & $4.5 \times 10^{16}$ & $1 / \theta \sim 1 / 4$ & $1.1 \times 10^{16}$ \\
\hline $\mathrm{V}_{\mathrm{DD}}[\mathrm{V}]$ & 4 & $1 / \theta \sim 1 / 4$ & 1 \\
\hline $\mathrm{V}_{\mathrm{sb}}[\mathrm{V}]$ & 0 & Eq. $(3)$ & +0.7 \\
\hline
\end{tabular}

$\theta$ : the temperature scaling factor, $\mathrm{T}$ : temperature $L_{\text {eff }}$ : effective channel length, $T_{o x}$ : gate oxide thickness $\mathrm{N}_{\mathrm{A}}$ : substrate doping concentration, $\mathrm{V}_{\mathrm{sb}}$ : forward substrate bias, $X_{j}$ (source/drain junction depth) $=0.3 \mu \mathrm{m}, W($ channel width $)=50 \mu \mathrm{m}$ 
Table 4.

Measured Device characteristics of $300 \mathrm{~K}$ and $77 \mathrm{~K}-\mathrm{TST}$ devices $\left(\mathrm{L}_{\mathrm{eff}}=0.3 \mu \mathrm{m}\right)$.

\begin{tabular}{|c|c|c|c|c|}
\hline & \multirow{2}{*}{$\begin{array}{c}300 \mathrm{~K} \\
\text { device }\end{array}$} & \multirow{2}{*}{$\begin{array}{l}77 \mathrm{~K} \\
\text { device }\end{array}$} & \multicolumn{2}{|c|}{ Scaling factors } \\
\hline & & & Experiment & Theory \\
\hline $\mathrm{S}[\mathrm{mV} / \mathrm{dec}]$ & 111 & 30 & $1 / 3.7$ & $1 / \theta \sim 1 / 4$ \\
\hline $\mathrm{V}_{\mathrm{th}}[\mathrm{V}]$ & 0.285 & 0.121 & $1 / 2.4$ & $1 / 0 \sim 1 / 4$ \\
\hline $\mathrm{I}_{\mathrm{DS}} \mathrm{S}[\mathrm{mA}]$ & $\left(\begin{array}{c}12.8 \\
\left(V_{D S}=4 V\right)\end{array}\right.$ & $\begin{array}{c}4.8 \\
\left(\mathrm{~V}_{\mathrm{DS}}=1 \mathrm{~V}\right) \\
\end{array}$ & $1 / 2.7$ & $\theta_{\mathrm{v}} \theta \sim 1 / 3$ \\
\hline $\begin{array}{l}\mathrm{Gm} / \mathrm{W} \cdot \mathrm{C}_{\mathrm{ox}} \\
{[\mathrm{m} / \mathrm{sec}]}\end{array}$ & $\begin{array}{c}4.6 \times 10^{4} \\
\left(V_{D S}=4 V\right)\end{array}$ & $\begin{array}{c}7.0 \times 10^{4} \\
\left(V_{D S}=1 V\right)\end{array}$ & 1.5 & $\theta_{\mathrm{v}} \sim 1.3$ \\
\hline $\begin{array}{l}\Delta \mathrm{S} \\
{[\mathrm{mV} / \mathrm{dec}]}\end{array}$ & 29 & 9 & $1 / 3.2$ & $1 / \theta \sim 1 / 4$ \\
\hline$\Delta \mathrm{V}_{\mathrm{th}}[\mathrm{mV}]$ & 115 & 33 & $1 / 3.5$ & $1 / \theta \sim 1 / 4$ \\
\hline
\end{tabular}

$\mathrm{I}_{\mathrm{DS}} \mathrm{s}$ : saturation. drain current, $\mathrm{G}_{\mathrm{m}} / \mathrm{W} \cdot \mathrm{C}_{\mathrm{ox}}$ : normalized transconductance; $\mathrm{G}_{\mathrm{m}}=\mathrm{I}_{\mathrm{DS}} / \mathrm{V}_{\mathrm{G}}$ (at $\left.\mathrm{V}_{\mathrm{DS}}=\mathrm{V}_{\mathrm{G}}\right), \Delta \mathrm{S}=\mathrm{S}(0.3 \mu \mathrm{m})$ $\mathrm{S}$ (long), $\Delta \mathrm{V}_{\mathrm{th}}=\mathrm{V}_{\mathrm{th}}$ (long) $-\mathrm{V}_{\mathrm{th}}(0.3 \mu \mathrm{m}), \theta_{\mathrm{v}}$ is the improvement factor of saturation velocity; $\theta_{\mathrm{v}}=\mathrm{v}_{\mathrm{s}}(77 \mathrm{~K}) / \mathrm{v}_{\mathrm{s}}(300 \mathrm{~K})=1.3$, where $v_{s}$ is the saturation velocity.

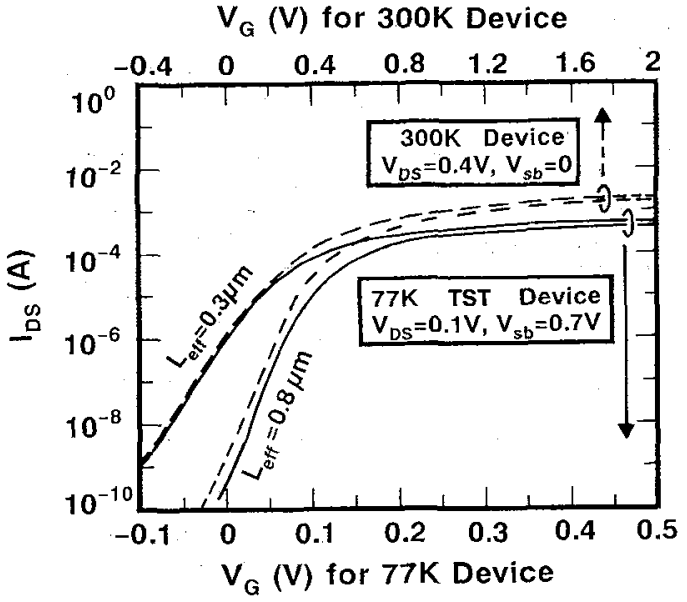

Fig. 4.

Measured subthreshold characteristics. The gate voltage $\left(\mathrm{V}_{\mathrm{G}}\right.$ ) for $77 \mathrm{~K}$-TST devices is scaled down to a quarter of that for $300 \mathrm{~K}$ devices. order to evaluate short-channel effects in TST devices. Electrical measurements at $77 \mathrm{~K}$ were made with the samples immersed directly in liquid nitrogen. The effective channel length $\left(\mathrm{L}_{\text {eff }}\right)$ is electrically determined by the linearregion channel resistance versus coded gate length curves with varied gate voltage. ${ }^{23}$ )

The measured device characteristics of $0.3 \mu \mathrm{m}$ MOSFET's are summarized in Table 4. Figure 4 shows the measured drain current $\left(\mathrm{I}_{\mathrm{DS}}\right)$ as a function of the gate voltage $\left(\mathrm{V}_{\mathrm{G}}\right)$ for $300 \mathrm{~K}$ and $77 \mathrm{~K}$-TST devices. The channel lengths are $0.8 \mu \mathrm{m}$ and $0.3 \mu \mathrm{m}$. The upper and lower axes of the abscissa correspond to the gate voltages for $300 \mathrm{~K}$ and $77 \mathrm{~K}-\mathrm{TST}$ devices, respectively. The forward substrate bias $\left(\mathrm{V}_{\mathrm{sb}}\right)$ for $300 \mathrm{~K}$ devices is $0 \mathrm{~V}$, whereas $\mathrm{V}_{\mathrm{sb}}$ for $77 \mathrm{~K}$ devices is $+0.7 \mathrm{~V}$ according to TST. The subthreshold slopes are found to agree well with each other, i.e., $\mathrm{S}$ and $V_{\text {th }}$ of $77 \mathrm{~K}$-TST devices are scaled down to $1 / \theta(\propto 1 / 4)$ as compared with those of $300 \mathrm{~K}$ devices.

Figure .5 shows the normalized transconductance $\left(\mathrm{G}_{\mathrm{m}} / \mathrm{W} \cdot \mathrm{C}_{\mathrm{ox}}\right)$ as a function of effective channel length $\left(\mathrm{L}_{\mathrm{eff}}\right) ., \mathrm{C}_{\mathrm{ox}}$ is the gate oxide capacitance. $\mathrm{G}_{\mathrm{m}}$ is defined as $\mathrm{I}_{\mathrm{DS}} \mathrm{s} / \mathrm{V}_{\mathrm{G}}$, where $I_{D S} s$ is saturation drain current at $\mathrm{V}_{\mathrm{G}}=\mathrm{V}_{\mathrm{DS}}=4 \mathrm{~V}$ for $300 \mathrm{~K}$ devices and $\mathrm{V}_{\mathrm{G}}=\mathrm{V}_{\mathrm{DS}}=1 \mathrm{~V}$ for $77 \mathrm{~K}$ devices. The saturation drain current $\mathrm{I}_{\mathrm{DS}} \mathrm{s}$ is found to be $12.8 \mathrm{~mA}$ for a $0.3 \mu \mathrm{m} 300 \mathrm{~K}$ device

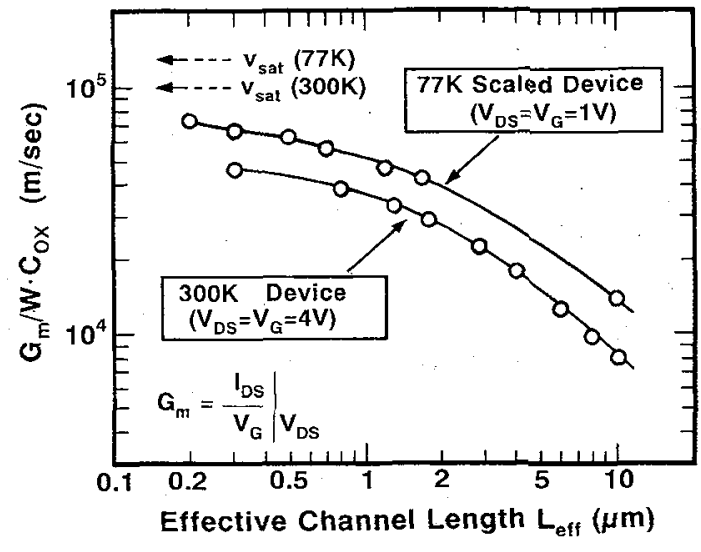

Fig. 5.

Normalized transconductance $\left(\mathrm{G}_{\mathrm{m}} / \mathrm{WC}_{\mathrm{ox}}\right)$ as a function of effective channel length $\left(\mathrm{L}_{\mathrm{eff}}\right)$. 
and $4.8 \mathrm{~mA}$ for a $0.3 \mu \mathrm{m} 77 \mathrm{~K}-\mathrm{TST}$ device. The saturation drain current ratio $\mathrm{I}_{\mathrm{DS}}{ }^{\mathrm{s}}(77 \mathrm{~K}) / \mathrm{I}_{\mathrm{DS}}{ }^{\mathrm{s}}(300 \mathrm{~K})$ is $1 / 2.7$, which is slightly higher than $1 / 3\left(\sim \theta_{v} / \theta\right)$ predicted by TST. $\theta_{\mathrm{v}}$ is the improvement factor of saturation velocity $\left(\mathrm{v}_{\mathrm{s}}\right) ; \theta_{\mathrm{v}}=\mathrm{v}_{\mathrm{s}}(77 \mathrm{~K}) / \mathrm{v}_{\mathrm{s}}(300 \mathrm{~K})$. The measured low-field mobility of the longchannel $77 \mathrm{~K}$-TST devices is found to be about 5 times larger than that of the $300 \mathrm{~K}$ devices. This improvement is considered to be due to both the low operation temperature and the use of low doping-concentration substrate for the $77 \mathrm{~K}$-TST devices. $\mathrm{G}_{\mathrm{m}} / \mathrm{W} \cdot \mathrm{C}_{\mathrm{ox}}$ for $77 \mathrm{~K}$ devices is improved by a factor of 1.5 as compared with that for $300 \mathrm{~K}$ devices. Although $\mathrm{G}_{\mathrm{m}} / \mathrm{W} \cdot \mathrm{C}_{\mathrm{ox}}$ for a $0.2 \mu \mathrm{m} 77 \mathrm{~K}-$ TST device reaches $7.4 \times 10^{4} \mathrm{~m} / \mathrm{s}, \mathrm{G}_{\mathrm{m}} / \mathrm{W} \cdot \mathrm{C}_{\mathrm{ox}}$ does not reach complete saturation. Consequently, the great improvement of $\mathrm{G}_{\mathrm{m}} / \mathrm{W} \cdot \mathrm{C}_{\mathrm{ox}}$ for the $77 \mathrm{~K}-$

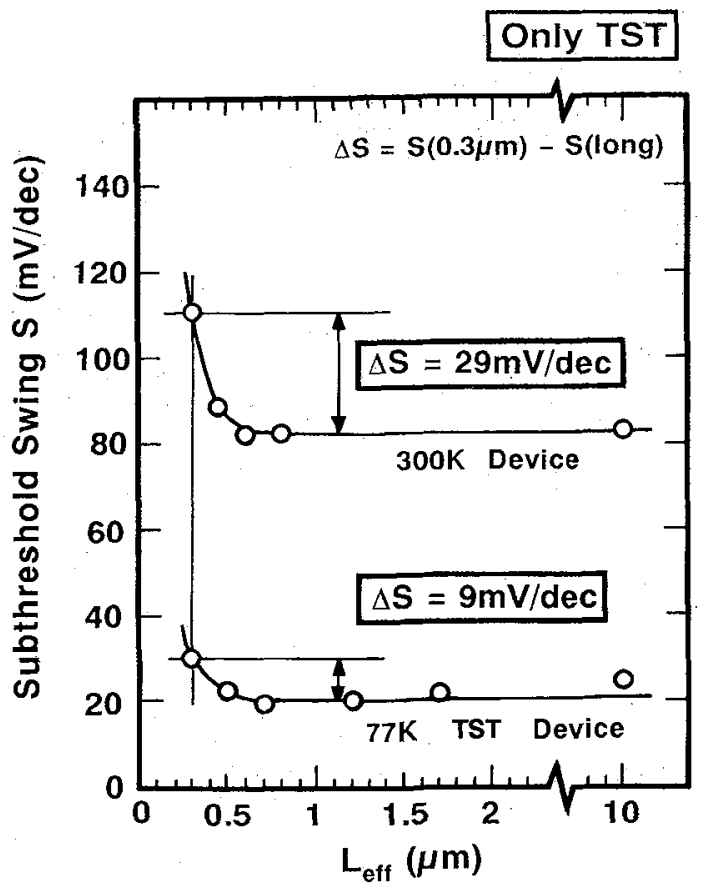

Fig. 6(a).

Measured subthreshold swing as a function of effective channel length ( $\mathrm{L}_{\text {eff }}$ ).
TST devices is considered to be due to the increases in both drift mobility and saturation velocity.

The subthreshold swing shift $(\Delta S)$ and the threshold voltage roll-off $\left(\Delta \mathrm{V}_{\mathrm{th}}\right)$ due to shortchannel effects are shown in Figs. 6(a) and 6(b), respectively. In these cases, the dimensional scaling is not applied; the substrate doping concentration and the gate oxide thickness are not changed when the channel length is decreased. S and $V_{\text {th }}$ of 77K-TST devices are scaled down to $1 / \theta(\propto 1 / 4)$ at any channel length as predicted by TST. It is also found that $\Delta S$ and $\Delta \mathrm{V}_{\text {th }}$ are nearly scaled down to $1 / \theta(\approx 1 / 4)$. Consequently, we have experimentally confirmed that the $77 \mathrm{~K}-\mathrm{TST}$ devices have the scaled characteristics of $S, V_{t h}$, $\Delta \mathrm{S}$ and $\Delta \mathrm{V}_{\text {th }}$

Only TST

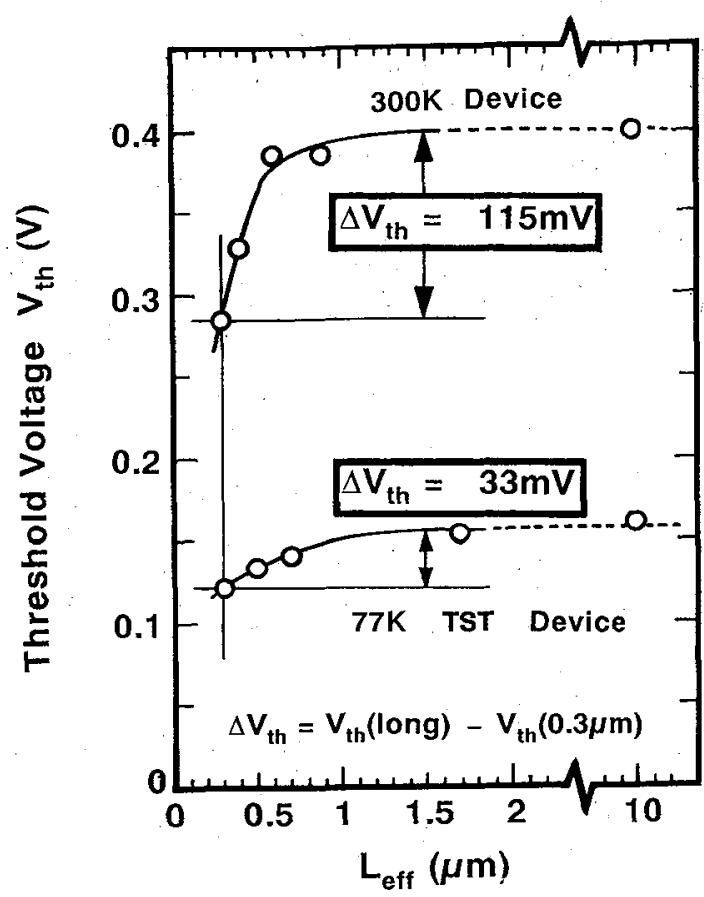

Fig. 6(b).

Measured threshold voltage as a function of effective channel length ( $\left.\mathrm{L}_{\mathrm{eff}}\right)$. 


\section{DEVICE CHARACTERISTICS OF FABRICATED 77K CST MOSFET}

In this section, we discuss the fabrication and the measured characteristics of 77K MOSFET's designed with the temperature-dimension combination scaling theory (CST) ${ }^{18,19)}$

Table 5 lists the device parameters. We first designed the $300 \mathrm{~K}$ device to have $\mathrm{V}_{\mathrm{th}}=0.8 \mathrm{~V}$ and to have no short-channel-effect (SCE) degradation at channel length down to $0.8 \mu \mathrm{m}$ : the gate oxide thickness and the substrate doping concentration were $25 \mathrm{~nm}$ and $4.5 \times 10^{16} \mathrm{~cm}^{-3}$, respectively. The supply voltage $\left(\mathrm{V}_{\mathrm{DD}}\right)$ of $300 \mathrm{~K}$ device is chosen to be $4 \mathrm{~V}$ for simplicity. Then, two types of $77 \mathrm{~K}-\mathrm{CST}$ devices, \#1 and \#2, were designed from the $300 \mathrm{~K}$-parent device. The temperature scaling factor is $\theta=4$, the dimensional scaling factor $(\lambda)$ is chosen to be $\lambda=2$ for device \#1, and $\lambda=8$ for device \#2. The voltage scaling factor $\kappa=1$ is adopted in this work for simple verification of CST. $V_{D D}$ of CST devices is scaled down by $1 / \theta \kappa=1 / 4$, i.e., $\mathrm{V}_{\mathrm{DD}}=1 \mathrm{~V}$. The forward substrate bias is designed to be $\mathrm{V}_{\mathrm{sb}}(77 \mathrm{~K}) \approx 0.8 \mathrm{~V}$ using $\mathrm{V}_{\mathrm{sb}}(300 \mathrm{~K})=0 \mathrm{~V}$, $\phi_{\mathrm{bi}}(300 \mathrm{~K}) \approx 0.9 \mathrm{~V}$, and $\phi_{\mathrm{bi}}(77 \mathrm{~K}) \approx 1.1 \mathrm{~V}$ in eq. (3). The threshold voltage $V_{\text {th }}$ for $77 \mathrm{~K}-C S T$ devices is predicted to be scaled down by $1 / \theta$ of that of $300 \mathrm{~K}$ devices, i.e., $\mathrm{V}_{\mathrm{th}}=0.2 \mathrm{~V}$. No $\mathrm{SCE}$ degradation is expected to be observed at channel length down to $0.4 \mu \mathrm{m}$ for $77 \mathrm{~K}$-CST device \#1, and $0.1 \mu \mathrm{m}$ for CST \#2. The junction depth of all devices are chosen to be as shallow as possible in order to clearly evaluate SCE degradation. The channel length were $50 \mu \mathrm{m}$.

$\mathrm{N}^{+}$-poly-silicon gate $\mathrm{n}$-channel MOSFETs were fabricated with a single-drain structure. $\mathrm{As}^{+}$ ion was implanted at $40 \mathrm{kV}$ and the implantation dose was $2 \times 10^{15} \mathrm{~cm}^{-2}$. The annealing for activation was carried out at $900^{\circ} \mathrm{C}$ for $30 \mathrm{~min}$. The junction depth was estimated to be $0.1 \mu \mathrm{m}$ from SUPREM-III simulation.

Figure 7 shows the measured subthreshold characteristics of the $300 \mathrm{~K}$-parent device and the $77 \mathrm{~K}-\mathrm{CST}$ device $(\# 2)$, respectively. The sourcedrain voltages $\left(\mathrm{V}_{\mathrm{DS}}\right)$ is $0.4 \mathrm{~V}$ for the $300 \mathrm{~K}$ device and $0.1 \mathrm{~V}$ for the $77 \mathrm{~K}-\mathrm{CST}$ device(\#2). The gate voltage axis for $77 \mathrm{~K}$ device is scaled by a factor of $\theta \approx 4$. The measured effective channel length $\left(\mathrm{L}_{\text {eff }}\right)$ of $300 \mathrm{~K}$ device is $0.88 \mu \mathrm{m}$, and that of $77 \mathrm{~K}$-CST device(\#2) is $0.18 \mu \mathrm{m}$. It has been clearly confirmed that $S$ and $V_{\text {th }}$ for the $77 \mathrm{~K}$-CST device are both scaled down to $1 / \theta(\approx 1 / 4)$ as

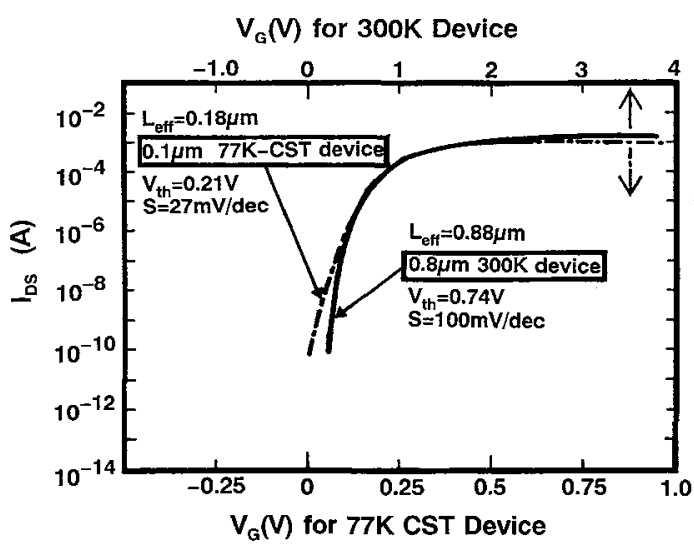

Fig. 7.

Measured subthreshold characteristics for $300 \mathrm{~K}-$ $0.88 \mu \mathrm{m}$, and $77 \mathrm{~K}-0.18 \mu \mathrm{m}-\mathrm{CST}$ MOSFET.

Table 5. Scaling factors and parameters of $300-\mathrm{K}$ and $77 \mathrm{~K}-\mathrm{CST}$ devices.

\begin{tabular}{l|c|c|c|c}
\hline & \multirow{2}{*}{$\begin{array}{c}300-\mathrm{K} \\
\text { device }\end{array}$} & \multirow{2}{*}{$\begin{array}{c}\mathrm{CST} \\
\text { Scaling factors }\end{array}$} & $\begin{array}{c}77 \mathrm{~K}-\mathrm{CST} \\
\text { device } \# 1)\end{array}$ & $\begin{array}{c}77 \mathrm{~K}-\mathrm{CST} \\
\text { device }(\# 2)\end{array}$ \\
\cline { 4 - 5 } & & & $(\theta=4, \lambda=2, \kappa=1)$ & $(\theta=4, \lambda=8, \mathrm{~K}=1)$ \\
\hline $\mathrm{T}[\mathrm{K}]$ & 300 & $1 / \theta$ & 77 & 77 \\
$\mathrm{~L}_{\min }[\mu \mathrm{m}]^{(\mathrm{a})}$ & 0.8 & $1 / \lambda$ & 0.4 & 0.1 \\
$\mathrm{~T}_{\mathrm{ox}}[\mathrm{nm}]$ & 30 & $1 / \lambda$ & 13 & 5 \\
$\mathrm{~N}_{\mathrm{A}}\left[\mathrm{cm}^{-3}\right]$ & $4.5 \times 10^{16}$ & $\lambda^{2} / \theta \kappa$ & $4.5 \times 10^{16}$ & $4 \times 10^{17}$ \\
$\mathrm{~V}_{\mathrm{DD}}[\mathrm{V}]$ & 4 & $1 / \theta \kappa$ & 1 & 1 \\
$\mathrm{~V}_{\mathrm{sb}}[\mathrm{V}]$ & 0 & See eq.(3) & 0.8 & 0.8 \\
\hline
\end{tabular}

(a) $\quad \mathrm{L}_{\min }$ : designed minimum effective channel length without short-channel-effect degradation. 
compared with those for the $300 \mathrm{~K}$ device. In the $77 \mathrm{~K}$-CST devices, source/drain punch-through was not observed even at $\mathrm{V}_{\mathrm{DS}}=2 \mathrm{~V}$.

Figures 8(a), 8(b) and 8(c) show $V_{\text {th }}$ and $S$ as a function of $\mathrm{L}_{\text {eff }} . \mathrm{V}_{\mathrm{DS}}$ is $0.4 \mathrm{~V}$ for the $300 \mathrm{~K}$ devices and $0.1 \mathrm{~V}$ for the $77 \mathrm{~K}-\mathrm{CST}$ devices. $\mathrm{V}_{\text {th }}$ and $S$ for the $0.88 \mu \mathrm{m} 300 \mathrm{~K}$ device are $0.74 \mathrm{~V}$ and $100 \mathrm{mV} /$ dec. In comparison, $V_{\text {th }}$ and $S$ for $0.18 \mu \mathrm{m} 77 \mathrm{~K}$-CST device $(\# 2)$ are $0.21 \mathrm{~V}$ and $27 \mathrm{mV} / \mathrm{dec}$. As predicted by the combination scaling theory (CST), the $77 \mathrm{~K}-\mathrm{CST}$ devices \#1 and $\# 2$ exhibit the SCE-free characteristics down to $\mathrm{L}_{\text {eff }}=0.38 \mu \mathrm{m}$ and $0.18 \mu \mathrm{m}$, respectively. It is confirmed that steep $S(27 \mathrm{mV} / \mathrm{dec})$ and low $V_{\text {th }}$ $(0.21 \mathrm{~V})$ for $1-\mathrm{V}$ operation are obtained without the SCE degradation at $\mathrm{L}_{\text {eff }}$ down to $0.18 \mu \mathrm{m}$ using CST. In this paper, we have demonstrated the nMOSFET characteristics. Enhancement type pMOSFET with $\mathrm{p}^{+}$-poly-Si gate can be designed according to the same manner; The dual-gate CMOS can be designed according to the combination scaling.

Recently, operation of sub-50nm MOSFETs with a supply voltage below $1.5 \mathrm{~V}$ at room temperature has been reported. ${ }^{24)}$ This report shows that MOSFET can be miniaturized below $50 \mathrm{~nm}$. However, $V_{\text {th }}$ has not been sufficiently controlled to be as low as $0.2-0.3 \mathrm{~V}$, which is needed for high current drivability with the low supply voltage. As described in this paper, based on the temperature-dimension combination scaling, $\mathrm{V}_{\mathrm{th}}, \mathrm{S}, \Delta \mathrm{V}_{\mathrm{th}}$ and $\Delta \mathrm{S}$ are scaled down to be adapted to the low-supply-voltage operation.

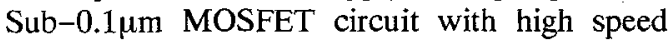
performance is considered to be designed based on the temperature scaling concept.

A promising application of the lowtemperature MOSFET is for super engineering workstation. Although a compact cooling machine with cooling capacity of $250 \mathrm{~W}$ (77K) and efficiency of $8 \%$ has been available, the efficiency should be further improved. The new packaging technology as well as the improvement of the efficiency are the most important key issues for the real application of the lowtemperature MOSFETs.

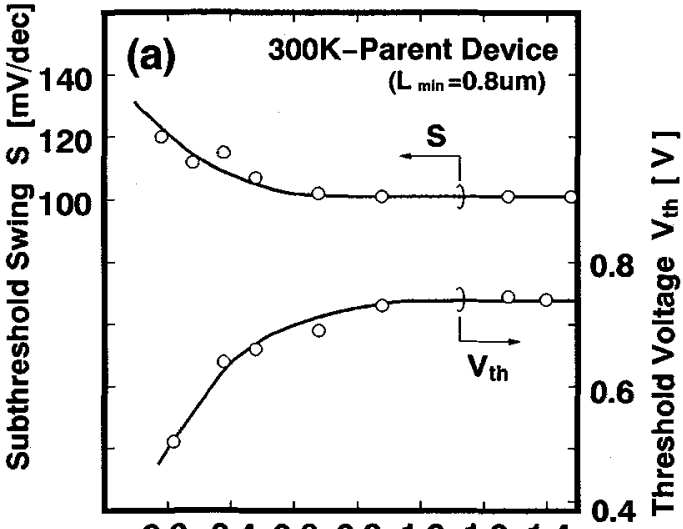

$\begin{array}{lllllll}0.2 & 0.4 & 0.6 & 0.8 & 1.0 & 1.2 & 1.4\end{array}$ Effective Channel Length L eff [um]

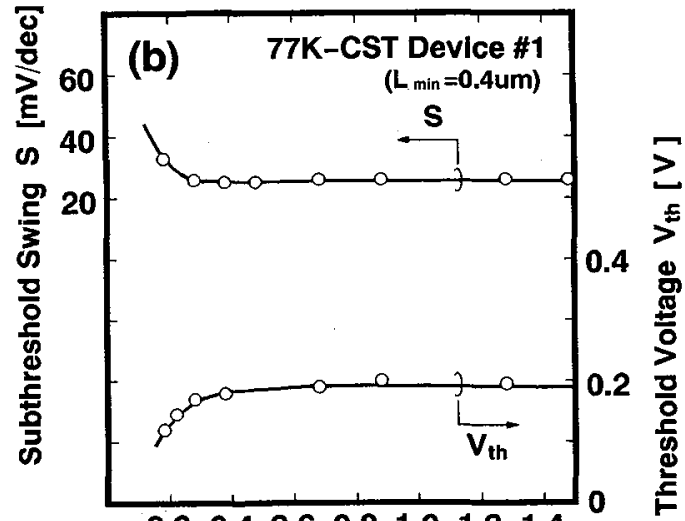

$\begin{array}{lllllll}0.2 & 0.4 & 0.6 & 0.8 & 1.0 & 1.2 & 1.4\end{array}$ Effective Channel Length Lefi [um]

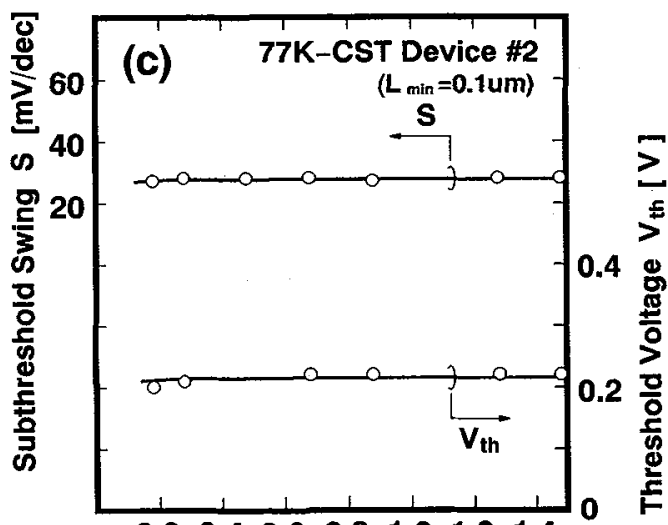

$\begin{array}{llllllll}0.2 & 0.4 & 0.6 & 0.8 & 1.0 & 1.2 & 1.4\end{array}$ Effective Channel Length Leff[um]

Fig. 8.

Measured subthreshold swing $(\mathrm{S})$ and threshold voltage $\left(\mathrm{V}_{\mathrm{th}}\right)$ vs. effective channel length $\left(\mathrm{L}_{\mathrm{eff}}\right)$. 


\section{SUMMARY}

We have proposed a temperature scaling concept for $0.1 \mu \mathrm{m}$ and below $0.1 \mu \mathrm{m}$ MOSFET. The temperature scaling theory is derived from the Fermi-Dirac distribution function and the distribution of mobile carrier concentration is maintained unchanged. In the temperature scaling concept, dimensional quantities are not scaled. 'In order to design $0.1 \mu \mathrm{m}$ devices, the temperaturedimension combination scaling theory has been proposed. We have designed and fabricated $77 \mathrm{~K}$ MOSFET with supply voltage of $1-V$ on the basis of the combination scaling theory. The subthreshold swing (S) and the threshold voltage $\left(V_{t h}\right)$ of the $77 \mathrm{~K} 0.18 \mu \mathrm{m}$ MOSFET with $1-\mathrm{V}$ supply voltage are both scaled down to $1 / 4$ $(\approx 77 \mathrm{~K} / 300 \mathrm{~K})$ of those of the $300 \mathrm{~K} 0.88 \mu \mathrm{m}$ device with $4-V$ supply. The 77K MOSFETs exhibit no degradation of $S$ and $V_{\text {th }}$ at the channel length down to $0.18 \mu \mathrm{m}$. The temperature-dimension combination scaling theory gives a design principle : for high-performance $77 \mathrm{~K} \quad 0.1 \mu \mathrm{m}$ MOSFETs with $1-V$ supply voltage.

\section{Acknowledgements}

The authors would like to thank Dr. Y.-W.Yi, Dr. M. Yokoyama and -Mr. T. Hidaka for their helpful discussions and their collaboration. This work was partially carried out at the Superclean Room of the Laboratory for Microelectronics, Research Institute of Electrical Communication, Tohoku University.

\section{References}

[1] R. H. Dennard, F. H. Gaensslen, H.-N. Yu, V.L. Rideout, E. Bassous and A. R. LeBlanc, IEEE J. Solid-State Circuits, SC-9 (1974) 256.

[2] J. R. Brews, W. Fichtner, E. H. Nicollian and S. M. Sze, IEEE Electron Device Lett. EDL-1 (1980) 2.

[3] R. H. Dennard, J. Vac. Sci. Technol. 19 (1981) 537.

[4] F. H. Gaensslen, V. L. Rideout, E. J. Walker and J. J. Walker, IEEE Trans. Electron Devices, ED-24 (1977) 218.

[5] M. Aoki, S. Hanamura, T. Masuhara and K. Yano, IEEE Trans. Electron Devices, ED-34 (1987) 8.

[6] G. A. Sai-Halasz, M. R. Wordeman, D. P. Kern, S. Rishton, E. Ganin, H. Y. Ng, D. Moy, T. H. P. Chang and R. H. Dennard, IEEE Electron Device Lett. 9 (1988) 633.

[7] T. Yamamoto, T. Mogami and K. Terada, in Tech. Dig. Symp. on 1992 VLSI Technol., Hawaii, 1992 (The Japan Soc. of Phy's., \& IEEE, 1992) p. 104.

[8] J. Koga, M. Takahashi, H. Niiyama and A.
Toriumi, Ext. Abst. the 1992 Int. Conf. on Solid State Devices and Materials, Tsukuba 1992 (The Japan Soc. Appl. Phys., 1992) p. 502.

[9] Y. Mii, S. Rishton, Y. Taur, D. Kern, T. Lii, K. Lee, K. Jenkins, D. Quinlan, T. Brown Jr., D. Danner, F. Sewell and M. Polcari, in 1993 Symp. VLSI Tech. Dig., Kyoto, 1993 (The Japan Soc. of Appl. Phys. \& IEEE, 1993) p. 91.

[10] M. Aoki, T. Ishii, T. Yoshimura, Y. Kiyota, S. Ijima, T. Yamanaka, T. Kure, K. Ohyu, T. Nishida, S. Okazaki, K. Seki and K.

Shimohigashi, IEEE Electron Device Lett. 13 (1992) 50.

[11] Y.-W. Yi, K. Masu, K. Tsubouchi and N. Mikoshiba, Jpn. J. Appl. Phys. 27 (1988) L1958.

[12] K. Masu, Y.-W. Yi, K. Tsubouchi and N. Mikoshiba, in Proc. of the Workshop on Low Temperature Semiconductor Electronics, Burlington, 1989, (IEEE, 89TH0252-7) p. 104.

[13] K. Masu, Y.-W. Yi, K. Tsubouchi and N. Mikoshiba, Trans. Inst. Electr. Eng. Jpn.110C (1990) 413. [in Japanese]

[14] K. Tsubouchi, K. Masu, Y.-W. Yi and N. Mikoshiba, Oyo Butsuri 59 (1990) 1484. [in Japanese]

[15] Y.-W. Yi, K. Masu, K. Tsubouchi and N. Mikoshiba, IEICE Trans. E74 (1991) 1641.

[16] Y.-W. Yi, K. Masu, K. Tsubouchi and N. Mikoshiba, in Proc. of Symp. on Low Temperature Electronic Device Operation, Washington, DC, 1991, (The Electrochem. Soc., Pennington, 1991) p. 99.

[17] M. Yokoyama, T. Hidaka, Y.-W. Yi, K. Masu and K. Tsubouchi, Ext. Abs. of 1992 int. Conf. on Solid State Device and Materials, Tsukuba, (The Japan Soc. of Appl. Phys., 1992) pp. 499.

[18] M. Yokoyama, T. Hidaka, Y.-W. Yi, K. Masu and K. Tsubouchi, Jpn. J. Appl. Phys. 32 (1993) 419.

[19] M. Yokoyama, T. Hidaka, K. Sasaki, K. Masu and K. Tsubouchi, to be published in IEEE Electron Device Letters (1994).

[20] K. Masu, M. Yokoyama and K. Tsubouchi, Proc. of Int. Conf. on Advanced Microelectronic Devices and Processing, Sendai, 1994 (The Res. Inst. of Elect. Commun., Tohoku Univ., 1993) p. 285.

[21] D. R. Frankl, Electrical Properties of Semiconductor Surfaces (Pergamon Press, London, 1967) Chap. 2.

[22] G. Baccarani, M. R. Wordeman and R. H. Dennard, IEEE Trans. Electron Devices, ED-31 (1984) 452.

[23] J. G. J. Chern, P. Chang, R. F. Motta, and N. Godinho, IEEE Electron. Device Lett., EDL-1, 170.

[24] M. Ono. M. Saito, T. Yoshitomi, C. Fiegna, T. Ohguro and M. Iwai, 1993 IEEE Int. Electron. Dev. Meeting, Washington, D. C.; 1993 (IEEE, 1993) p. 119. 